\title{
Legitimising leisure experiences as emotional work: A post-humanist approach to gendered equine encounters
}

\begin{abstract}
Due to changes in lifestyle and work patterns, education, and values associated with wellbeing, non-human animals are now incorporated into a range of human experiences and environments (Franklin, 1999). This research specifically focuses on human-equine relations, examining blurred boundaries between therapeutic and recreational interspecies encounters. Birke and Brandt (2009) and Daspher (2015) acknowledge that human-equine relations are often gendered, and this research focuses mainly on women's narratives. Viewed through the post-humanist lens, horses now form kinship and companionship roles, particularly for women, where relations have become mutually emotionally dependent as result of interspecies communication and embodied encounters. Research utilises feminist post-humanist (Barad, 2007; Braidotti, 2013; Haraway, 2003) and cultural politics of emotion (Hochschild, 1983; Ahmed, 2004) frameworks as situated in Latimer and Burke's (2009) work on the co-agency of animals. Embedded in Danby's (2017) concept of equiscapes, or post-humanist leisure spaces, research methods employ qualitative approaches, including in-depth interviews, participant diaries, and multi-species ethnography. Findings reveal how women make considerable investments in equine activities, which develops mutual welfare and wellbeing. Yet, despite these benefits, emotional and other expenditures are justified in work discourses to legitimise them as valuable to themselves, their families, and their communities.
\end{abstract}

\section{Introduction}

A horse weighs about a thousand pounds, can run faster than thirty five miles per hour, and has the mental and physical characteristics of a prey animal rather than a predator. Yet, despite these formidable and often intimidating differences, humans invest love and attention - not to mention considerable financial resources - to care for these gentle goliaths (Keaveney, 2008:444).

As Dashper (2017:1) indicates, "There has been growing academic interest in critically examining human and non-human animal relationships and questioning how we, as humans, should think about, treat, and care for the animals who are important participants in our day-to-day lives." This paper focuses on the interrelations between women and horses, specifically the reciprocal care and emotional bonds that result in mutual wellbeing. In this research, human-horse relationships are re-conceptualised in accordance with Wilbert's (2009) notions surrounding networks of interdependencies focused around empathy, sentimentalisation, and kinship. This paper unveils an 'animal turn' in theorising human-equine relations; previously, horses were understood as existing for human consumption and utilisation. A post-humanist shift has occurred, and human attitudes and interactions now are embracing an appreciation of horses for their intrinsic values and as significant actors in the relationship. Much research to date explores human-equine relations through a humanist lens by exploring the wellbeing effects of such interactions for humans (Davis et al., 2014; Hallberg, 2008; Irwin, 1998; McCormick et al., 2000; Roberts, 1996; Toth, 2002). Moreover, Hallberg (2008) argues the custodianship of horses because they assist humans in learning, growth, and 
change. However, more recently, there has been a significant shift in human-animal relations and understanding, where non-humans are acknowledged as also fundamentally important beings in the universe (Carr, 2015; Danby and Hannam, 2016; Danby, 2017; Dashper, 2017; Markwell, 2015). As the above Keaveney (2008) quote suggests, this has led to the formation of sentient and empathetic humananimal interactions through moral consideration and sense of reciprocal partnership.

This paper situates itself theoretically with Latimer and Birke's (2009:2) work on "the co-agency of animals and humans in the co-construction of social worlds." They argue, "working, playing and being with horses can itself be performed as a way of life, as opposed to simply one more accessory to a lifestyle." The co-constructed social world that is the focus of this paper is embedded in the conceptual spaces of the 'equiscape' (Danby, 2017). Equiscapes are settings which allow humans insight into the lives of horses by interacting in and acknowledging the world from the horse's perspective. This research is situated in this horse-focused landscape in order to critically examine how work is re-imagined within leisure settings. Equiscapes are the practical manifestation of the post-humanist concept, as humans and non-human animals are considered equals and work together as companions. Equiscapes encourage interconnectedness, emotional exchange, and cross-species communication, and can result in positive mutual understanding and the development of trusting relationships (Danby, 2017). By providing temporal, natural spaces where humans can escape from mundane routines by crossing boundaries and emerging into the horse environment to interconnect and develop relations through various activities within the leisure landscape, equiscapes involve emotional recreation as humans and horses are able to gain intellectual, physical, and spiritual stimulation from their interactive experiences. Feminist post-humanist approaches reveal that women and horses have the ability to coexist effectively through mutual trusted partnerships and understanding. Once in close confinement with horses, women's self awareness and life perceptions suddenly alter, where the horse becomes the sole focus (Danby, 2017). This espouses post-humanist ideals whereby humans are able to view the world through a non-human lens. Also, horses are seen to undertake a 'feminised' caring role, and demonstrable emotional labour on the part of horses completes the reciprocal give-and-take nature of these kinds of relationships. Equiscapes encourage interconnectedness and cross-species communication to occur and can result in positive mutual understanding and the development of trusting partnerships (Danby, 2017).

This research draws together post-disciplinary concepts related to gender identity and performance (Fullagar and Pavlidis, 2017), leisure as labour (Rojeck, 2009), and human-animal emotional bonds (Dashper, 2015). Theoretical frameworks have been adopted and adapted to intersect post-humanism (Wolfe, 2013) from feminist perspectives (Haraway, 2003) with critical animal studies (Adams and Donovan, 1999) in the contexts of emotional recreation (Danby and Hannam, 2016). Such cross-fertilisation is scarce in the literature; therefore, this paper contributes to critical understanding of gendered human-animal relations in leisure spaces.

This paper begins by setting the context in which gendered human-equine relations may be formed. The research is embedded in theoretical underpinnings exploring post-humanist perspectives of gendered human-equine relations. As part of this, critical feminist approaches are applied in order to deepen understanding of women's emotional relationships with their horses. The analysis and discussion of the main themes derived from qualitative methods illustrate how women and horses interrelate within the leisure landscape of the equiscape. Here, it becomes obvious how women and horses have developed sentimentalised relations through a myriad 
of leisure pursuits where both 'actors' have become mutually dependent for emotional, physical, and overall wellbeing. As a result of serious investment in time, emotional, and financial commitments, it was found that women validate and value their caring encounters and human-equine bonds by framing their dedication in work and therapeutic terms. It becomes clear that the women view horse-related activities as more than a pastime; the paper concludes exploring how women's horse-related experiences become markers of their identities, a prominent component of their sense of self and self worth.

\section{Literature Review}

\section{Post-humanism and gendered human-equine relations}

Post-humanist theory combined with critical animal studies challenges the singular focus around human subjects, blurring boundaries between the human and nonhuman, looking beyond human agency and exploring and developing the 'other' agency within the relationship (Adams and Donovan, 1999). Wolfe suggests the challenge of post-humanism is when 'the animal' becomes simply another object of study (Feder, 2014). Indeed, Feder (2014:266) supports this by stating, "Posthumanism may challenge the primacy of humanity, the idea of the Human as the allpervasive legacy of Enlightenment essentialism... It also signals a renewed interest in the biological world, ideas of human animality and our kinship with other creatures." A post-humanist approach to human-animal relations seeks to explore innovative ways of being part of society, with emphasis being placed on what Wilbert (2009) refers to as the human-animal divide from one of oppositional dualism into networks of intricate dependencies focused around kinship.

We align post-humanist approaches with what Adams and Donovan (1999:3) term, "broader feminism", meaning "incorporating within it other life forms besides human beings." By adopting feminist post-humanist approaches, this paper recognises the relational and emotional capabilities of interspecies interactions (Gruen, 2011) and draws on Barad's (2007) theories of intimate entanglements and intraction, where both parties change as a result of their meeting. Birke (2002) asks, "How does gender become performed whenever we observe animals?" In an effort to shed light on this, and rooted in feminised caring traditions, this paper focuses specifically on women's experiences of interacting with horses, as they are not as prevalent and arguably not as prioritised in the literature relating to human-animal relations. Although understanding of gender is generally accepted to be socially constructed, performative, relational, and moving away from dualisms (Butler, 2006), Birke (2002:432) argues that "while feminist theorists emphasise the fluidity of gender, the same theory assumes an underlying fixity of nature and animals." This, it is argued, is due to the cultural history of animals and women being both linked as 'others', which has acted as justification for their alleged inferiority to men, and, thus, interconnects their oppressions (Adams and Donovan, 1999). Feminist posthumanists Braidotti (2013) and Haraway (2003) argue humanist approaches are (white) male-centric and support false dualisms, such as those between human and non-human animals. These dualisms are promoted based on the premise that "humans' and animals' needs are in conflict. It also implies human needs are paramount, reinforcing a status hierarchy that has favored neither women nor other animals" (Admas and Donovan, 1999:3). Haraway (2003) argues that nature and culture are not oppositions; rather, there is an ongoing process of 'becoming with' each other in natural cultural practices. She and other feminist post-humanists argue that it is men who promoted such oppositions through dominance, and "anthropocentrism is fed by sexism" (Adams and Donovan, 1999:5). 
animals. However, limited accounts demonstrate how animals are able to evade such domination, where animals have been generally regarded as a relatively powerless and marginalized 'other' partner in human-animal relations (Philo and Wilbert, 2000). Philo and Wilbert (2000) argue that humans should look for human 'courtesies' towards animals, allowing them the decencies of life, space, and place that we (humans) would expect and want for ourselves and others in a manner that does not stem from anthropomorphism, but which also objects to a crass anthropocentrism. Latour (1988) adopts the philosophical stance and argument of hylozoism, which holds a view that 'all' matter, acknowledging that everything in the world has a role or place whether it be of humans, non-humans, plants, or organisms for example. Within this paper, findings demonstrate an equalling of power within the human-equine relationship demonstrating that both human and horse respect and trust each other in order to effectively interconnect. Reflecting upon animal welfare, much literature demonstrates the notion that animals are equally as important as humans in the world and should, therefore, obtain the same level of appreciation, respect, and welfare as humans (Philo and Wilbert, 2000).

In the absence of human language for communication by horses, they are highly sensitive to sensory stimulation and communicate through means of sight, touch, smell, sound, rhythm, and kinesthetic cues. Irwin (1998) suggests that horses need to feel respect for humans; although, respect is earned through competency and confidence in humans through riding, general care, and welfare along with interconnectedness. Hallberg (2008) refers to interconnectedness in that horses can sense through minimum actions, body posture, smells and tone of voice how the human is doing emotionally and physically, asserting that every single movement he or she is in the presence of horses, communications occur. She explains that everything the human does and thinks, every emotion that the human has, is taken in by the horse, assessed and utilised. This opens up the door to cross-species communication and describes a form of social exchange. As a result, humans and horses learn how to be together, how to interact and move together through the bodies of each partner (Dashper 2017) and by observing bodily postures. Therefore, both partners play an equal role in the exchange and are able to anticipate and acknowledge the needs and interests of the other (DeMello, 2012). Being at 'one' with the horse involves a form of interconnectedness through feelings of haptic and tactile sensations which are picked up and transferred through what Hallberg (2008) refers to as 'entrainment' between humans and horses, particularly whilst riding. The blurring of human and horse bodies during riding allows both actors to experience the world physically and spiritually, interacting with their minds, personalities, sensations, and emotions whilst in motion (Danby and Hannam, 2016).

Horses are large herbivores that require space and intense management, exercise, feeding, and grooming (Birke, Hockenhull and Creighton 2010). Thus, it needs to be noted that horses are considered important actors within the human-equine relationship, worthy of significant, moral thought and consideration within work and leisure landscapes. There are reciprocal benefits to human-horse interactions. Human interaction is fundamental for horses due to their social nature. Consequently, Hama et al. (1996) reveal that human-animal interaction is good for horses, as stress levels decrease when petted as well as other benefits associated with grooming and exercise. Companion animals have a 'social place' in daily routines, and when humans interact with such animals, they are interacting with an animal that they relate to as an individual sentient being associated as a companion and/or family member. Such relations are not structured only by human needs and interests, but also by the animals' (DeMello, 2012). 
From a gender point of view, traditionally, the human-horse relationship has been male dominated (Robinson, 1999), reflecting the role of the horse as a work tool and a symbol of power and prestige. This is especially the case in employment environments where men were mounted on horses for military, police, and other outdoor occupations. This is still evident in today's society, where horses are used for the Cavalry Guards, mounted police forces, and farming/ranching, which are mostly professions that are considered to be dominated by men. However, Dashper (2015:2) notes the shift in humans using horses in "agriculture, warfare, and transport" to being "predominantly a partner in human sport and leisure."

As part of this shift away from work towards leisure pursuits, the human-equine relationship has also changed with an inclusion of more women, who have increasingly become involved with horses through recreation, riding as a sport or hobby. This has signified a "feminisation of horse riding and the horse industry" (Dashper, 2015:351). A BHS (2012) survey supports this argument, suggesting that $73 \%$ of riders within the UK are women, which demonstrates a shift in gender relations with horses. From a horse perspective, Henry et al. (2005) suggest that there is no evidence that the gender of the human has any impact on the behaviour of the horse; instead, the horse's own temperament is a substrate on which experiences will model the way horses respond to humans (Hausberger, 2008).

Birke and Brandt (2009) further highlight that for many girls growing up around horses, riding enables opportunities to challenge conventional concepts of femininity. 'Messing around' with horses allows them to perform outside normative gender roles, such as getting dirty and strong through physical activities. It also helps to develop self-esteem and confidence (Traeen and Wang, 2006). As Dashper (2015:12) argues, "Equestrianism offers women many opportunities to redo feminine gender roles in small ways that open up feminine identities that are active, physically capable, and knowledgeable." Within her analysis of the psychology of women and horses, Toth (2000) notes that women and girls enjoy the power and speed of horses; however, they also enjoy the closeness of physical and emotional contact with a horse and tend to seek an intense one-to-one relationship as a friend and confidant. She mentions that boys also ride, but it is girls who spend hours grooming and pampering horses, illustrating one of the fundamental gender contrasts between men and horses and women and horses.

\section{Interspecies emotional encounters}

Feminist scholars, such as Hochschild (1983), have led a re-evaluation of understanding emotions from personal psychological 'dispositions' to performances of expected gender social norms. Ahmed's (2004) seminal work on this subject argues emotions are cultural practices and, therefore, relational. This means emotions can be personal sensations while also being collectively culturally imagined within social communities. Therefore, people feel and act on emotions in ways that conform to popular value systems, such as those involving gender roles and patterns of behaviour. This externalising of the internal can be seen as political, especially when examining "essentialising discourses that position women's subjectivities as 'naturally' more emotional than men (more caring and less rational) and opens up questions about how emotion is gendered through the embodied performance (doing) of self-other relations in everyday contexts" (Fullagar and Pavlidis, 2017, p. 8).

Dashper (2015) also acknowledges that caring and nurturing aspects of horse welfare are usually performed by women. Despite the many challenges to 
conventional gender roles and binary identities by equestrianism, she argues that women tend to be positioned as 'natural carers', which is undervalued in opposition to men's so-called 'rational expertise' (Dashper, 2015). The feminisation of the emotional in equine-related relationships is complex, as, on the one hand, caring activities are not fully respected due to women's subordinate standing in patriarchal society (Husso and Hirvonen, 2012); yet, on the other hand, these nurturing practices are crucial for mutual wellbeing of women and companion horses. It is argued that care work is valuable and should be more highly valued (Nishikawa, 2011; Hamilton, 2011). This is especially the case in human-horse relationships, as acts of caring increase mutual welfare. Although embracing conventional feminine identities of the carer and the nurturer do not threaten normative gender roles, most women equestrians find ways to fulfil personal passions and develop confidence through the physical power and emotional connectedness they feel when they are with their horses.

Likewise, horses can be seen to provide emotional support for their companion humans through "symbolic interactionism" and nonverbal communication for the creation of shared meaning (Brandt, 2004:299). Although equestrianism is predominantly viewed as emotional recreation for women, horses also espouse feminine-associated caring roles. Whether the horse is male or female is not a factor in its caring behaviour; it is only humans who assign 'gender' to emotions and behaviours. Birke (2002:432) states, "Animals learn to perform a role emerging from their relationships with people... Domestication could be a historical process of performances of the roles of companion animal and human caretaker deeply intertwined." There are parallels in affecting behaviours performed by women and horses with each other. It should be noted that these feelings are not always reciprocated, as questions of power and agency (human and horse) can be factors, especially when both participants do not acknowledge each other as equals or deserving of respect. However, as this research demonstrates, matching emotional care between species is not only possible, but also becomes meaningful as embodied relationships develops over time.

Often, human emotions are validated and valued (at least personally) by framing them in work terms or as medical/psychological conditions, which require work to address. On many levels, the amount of time, effort, and resources required to pursue equine leisure pursuits is justified by re-positioning it as emotional work and/or physical work. This relates both to the human, who frames it as work for self improvement and work for horses' welfare, and also for the horse, who works by riding and engaging in physical activities with humans. Swan (2008) suggests relations between processes of emotionalisation in society, therapeutic cultures, and new forms of emotional subjectivity and self-presentation has led to heightened awareness of emotional selves, which permeates all aspects of life. Equestrianism is often seen as part of therapeutic treatments for mental illnesses. As a respondent for Davis et. al.'s (2014:298) study on the medicalisation of pleasure among women equestrians stated, "Riding makes me happy... At the barn I am at now, there are some like-minded people like me in that their horse is there for psychotherapy. They don't go for counselling; they go to their horse. They talk to their horse. They love their horse. They are very connected to their horse." As Daly and Morton (2006:113) indicate, "A growing body of empirical research over the past two decades points to the value that human-animal interactions have for individuals, benefiting them in psychological, physiological, and emotional ways." Hallberg (2008) affirms that the process of getting to know horses is exciting, challenging, and healing. Davis et al. (2014) describe this as blurring of boundaries between therapeutic and recreational 'work', explaining that there is a societally-driven need to put experiences in these 
terms in order to legitimise pleasure and dedication.

The following sections discuss the research methods used within this study and an analysis of the research findings. One of the key points of which to be aware are how women (re-) formulate their own identities in relation to their horses and define themselves by the amount of 'work' they put into their equestrian pursuits. As a result of interspecies communication and embodied encounters through emotional and physical care, horses form kinship and companionship roles for women equestrians. Interactions with non-human animals can be revealing about our true natures, expressing to ourselves and others who we are and who we want to be (Herzog, 2017). Knight (2005:1) argues, "Animals inhabit the human mind or imagination as well as the physical environment. Human beings draw on animals to think about themselves."

\section{Research Methodology and Methods}

Post-humanist insights provide an interpretative, empirical approach towards human-equine relations and emotional encounters. This research has been conducted within equiscapes, which are leisure environments where post-humanist approaches are enacted for the reciprocal relational benefits for both actors. For the purpose of this study, data was collected using a qualitative multispecies ethnographic approaches, which are considered effective methods when studying interactive human-animal relationships, as recording, observation, and interpretation of lived experiences can complement other methods to increase the validity and reliability of the findings (Davis et al, 2014). In-depth interviews, individual diaries, and human-equine observations were conducted at an equestrian organisation in the northeast of England, and the sample drawn from their regular recreational users. This included a range of women participants, predominantly white, British citizens, aged between 18-65 years of age. Participants had varying professions, which ranged from policewomen, students, teachers, florists, retirees, to name a few. Participant experience with horses varied considerably, from beginners to intermediate and advanced riders. Some of the sample included participants who had equestrian careers. This sample was chosen because it provided a varied inclusive cohort of participants from various age groups, professions, social groups and different levels of experience and expertise of horses and individual equestrian activities. Individual names of interview respondents and associated horses were changed to ensure anonymity. The interview sample consisted of 21 respondents, and the diary sample consisted of 15 completed diaries. Participants either spoke or wrote about their interactions and emotional encounters with horses within leisure landscapes along with displaying bodily signals and emotion through specific physical interaction with their horses. Participants interacted frequently with horses through participation in a range of equestrian pursuits including riding, horse welfare, learning about horsemanship and equine culture, competing, or equestrian tourism engagement. For some participants, horse ownership was evident whereas others loaned or interacted with various horses on a regular basis. Participant observations were incorporated into the study by providing complementary visual data to enhance the validity of the qualitative approaches. Personal diaries were completed by participants to keep a log of individual interactions, experiences, and emotions as a result of human-equine relations and associated equestrian pursuits in order to enrich the data by providing insight into private, reflective thoughts. Diary participants remained anonymous to encourage more open discussion surrounding their emotions and experiences with horses. Once transcribed, data from the interviews and diaries were coded, and fundamental themes were identified encompassing human-equine relational encounters and equine leisure engagement. 


\section{Findings and Discussion}

\section{Gendered empathetic relations}

Within the emerging field of critical human-animal studies, Birke and Brandt (2009) refer to researchers who have explored various questions relating to human interactions and experiences with non-human animals. However, they argue that much work focuses more specifically on people's lives with dogs and cats, and few studies address species such as horses. Although Birke and Brandt (2009) highlight that girls and women predominate most areas associated with equestrianism, especially at amateur levels, there is a paucity of literature addressing questions of gender inclination and gender performances in relation to non-human animals. Birke and Brandt (2009) suggest that humans and horses create a kind of intimacy when connected through embodiment, and the co-operation needed for riding should come from mutual affection and not domination, which had previously been the prevailing approach (Mills and McNicholas, 2005). This can be seen to be the case for the women respondents in this study. Although none of them knew or consciously chose to view their relations with horses through a post-humanist lens, they adopted this approach regardless. The following statement made by Belinda articulates the sense of closeness and intimacy she had with her horses:

Belinda, aged 60, horse-owner:

We just bonded because we went through thick and thin together. I don't think you can go through life threatening experiences, which you do on horseback with any other pet, and I just learnt to just get on with her really well, and, in the end, we were so close but equally the mare I only had for one and a half years. I was so close to her because I felt she looked after me. She wasn't crazy - she was totally sensible, and we just got on really well, and I think she knew that I was looking after her when she was ill. I mean, I did everything that I possibly could you know, vets, I took her to the beach to live, we tried essential oils - aromatherapy, I tried everything, I had breathing apparatus for her - you name it I tried it! I think she knew that I was trying to help her, and I just think there's a strong bond particularly, I think, between women and horses. Oh, there's no feeling like it; it's just lovely!

It is interesting to note how Belinda talks of how her and her horse went through 'thick and thin' together, illustrating that she went through some life threatening experiences on horseback. Keaveney (2008) reaffirms the creation of bonds between humans and their horses, arguing that horse and rider bonds develop in the aftermath of getting through a particular tough or awkward situation together, stating that in some cases when the human is in trouble, the horse takes care of them, which reinforces the close sensation and unification of working partnerships. This is evident in Belinda's statement, illustrating that some of the experiences that her and her horse encountered brought them closer together through the formation of a robust bond, and her horse 'looked after' her in a reciprocal caring relationship. Keaveney (2008) further notes that sometimes the bond develops when the horse is in trouble, it trusts the human to take care of it, which again signifies this two-way trusting partnership. The following diary extract signifies the element of mutual trust which has built up between the human and horse over time:

Anonymous diary extract:

I'm able to trust him; we have built a trusting relationship.

However, Keaveney (2008) argues that horses think differently to humans. In contrast to humans as predators, horses are prey animals; therefore, horses have a highly developed set of physical characteristics that help them to survive (Budiansky, 
1997). Keaveney (2008) suggests that horses socialise differently from humans in accordance with herd animal instincts. As herd animals, their primary attachment is to the herd and fitting into a strict social hierarchy. Horses do eventually develop attachment to their owners, but horses and humans essentially have an insider versus outsider relationship (Keaveney, 2008), alerting us to a sense of 'otherness' associated with horses. This means humans need to be aware of these different behavioural traits and to learn, accept, and respect such differences in order to form effective relationships, which reinforces the post-humanist mode of thought.

Keveney's (2008) work also illustrates that most of her informants reported strong feelings of friendship towards their horses and speculated that their horses considered their humans to be their friends, protectors, and caretakers. This further illustrates Barad's (2007) theories of intraction, as the participants in this research have developed intimate entanglements with each other, which have led to the cocreation of affective behaviour and complex somatic attachment. This was also reported by multiple participants for this research:

Sharon, aged 40, horse-owner:

If you've got a horse to look after or you've got an animal to look after, the love and affection that you get back from them, it's unconditional, you know, and it's just lovely that something with a mind of its own has chosen you to love as much as you love it, and I think that's just amazing - absolutely amazing.

Jane, aged 55, horse-owner:

You just feel like you've got a best friend; he's not gonna let you down. You know that sort of closeness that you feel.

Women interviewed for this study referred to their horses as family members, which dilutes the sense of 'other' and reinforces the notion of equality within the relationship by not considering themselves as superior. The statements demonstrate the spatial separation of humans and horses, as horses are unable to share houses with their humans; however, despite this, humans are aware that they both still coexist in close proximity. Some horses were kept very close to the participants' homes; whereas, others were kept at a local livery yard. The participants frequently discussed that due to this distancing of habitats, they frequently made conscious efforts to go to the horses' environments to interact and care for their welfare just like they would do for another family member. Keaveney (2008:10) refers to a quote made from one of her informants surrounding horse ownership: "Horse ownership, like having children, is not for the faint of heart. If you use your horses, live with them out on the trail, work with them, really care for them...horse ownership will affect your life". This was found to be the case with women participants for this research. Many referred to their horses in filial terms, which exemplifies the nurturing aspects of rider-horse relationships. This is seen as a positive reciprocal welfare relationship, which has mutual benefits. Even though the horses do not inhabit human houses, they still coexist in imagined spaces and remain close within the human's mind and are therefore associated with kinship, which is evident by the statements by Lesley and Jade below:

Lesley, aged 31, Instructor and horse-owner:

My horses are like my kids. I haven't got any kids obviously, but that's what I treat them like. You look after them and make sure they've got everything that they need, 
and, in turn, they give you back the same feeling that you look after them. And just being with them can - sometimes, if you're upset or unhappy, your horse calms you down and things like that.

Lesley's statement sets out a motherhood narrative in that she describes putting in the emotional work in order to foster mutual love and reciprocal care.

Jade, aged 21, horse-owner:

It's like mother and son [laughs]. Oh I love my horse! It's more like a team as well. If I go away, he looks after me. It's just like... he's my little man! [laughs]. He's my son [laughs].

It can be seen from Jade's statement above how she relates her relationship with her horse to a mother and son relationship and expresses her love for her horse in maternal terms. Similarly, Jones (1983) reported that the majority of riders considered their horse to be part of the family and most of them related to their horse as if it were a child. However, Jones (1983) also suggests that men riders more frequently referred to the horse as an adult family member rather than evoking paternal imagery. It is important to note that although Jade describes a mother and son relationship with her horse, she also mentions their partnership since he looks after her when she is riding him. The importance of mutual trust and respect is evident again here; as Keaveney (2008) states, riders trust horses with their lives, and, in return, the horse recognises that trust is a two-way process.

\section{Recreational and therapeutic 'work'}

Within the leisure landscape, humans interact with horses in many ways (Danby, 2017). Robinson (1999) acknowledges the complex associations humans have with horses, whereby some own their horse whilst other may loan; others may engage in equestrian pursuits as a recreational activity. Some horses inhabit spaces close to their humans; whereas for many, they are kept at local livery yards. Horse keeping is labour intensive; along with riding, horses require daily care and devotion as well as substantial financial commitment (Danby, 2017). As Dashper (2015:9) argues, "Caring and training of horses must be done daily regardless of weather, human health, or inclination... Daily manual labour is required to 'muck out' stables, carry hay, straw and heavy buckets." Although there is hard work involved, this is viewed as satisfying and rewarding. Human-equine leisure pursuits and associated experiences provide an essentially hedonistic activity, allowing for pleasurable interaction and the opportunity to develop relationships between humans and nonhumans (Danby, 2017). In these equiscapes, or sites of human-horse interaction, there is a blurring of boundaries between humans and horses through varied encounters and activities. This leads to what Game (2001) refers to is an inbetween' stage where the human becomes part horse, and the horse becomes part human through their interactions, particularly riding. This interconnectedness between the two species, and the need to respect and understand each other's differences, is essential to communicate effectively with each other (Game, 2001). To work effectively with horses, humans need to respect difference and to understand the culture of the horse. Once humans adopt this perspective, they are able to interact and relate to the horse more successfully (Game 2001). As a result, positive human-equine experiences may evolve, which encompass 'emotional' recreation, as humans and horses are able to gain intellectual, physical, and spiritual stimulation from their interactive experiences (Danby, 2017).

Keaveney (2008) explains that a 'horse person' loves and reveres horses, needs to 
be around them, and make large sacrifices in terms of time, money, and energy to engage with them, often to the puzzlement or even distress of the rest of their families. Emotional devotion is not necessarily viewed as rational when the focus is a non-human animal; for example, if women were making these kinds of sacrifices for their children, it is doubtful that it would be an issue among wider society. When humans empathise with and dedicate time, resources, and deep emotional reserves to non-human animals, their passion and practices come under question and require explanation because their behaviour is seen as atypical and outside the societal accepted norms of emotional expression (Ruberg, 2010). A kind of pejorative mental illness language is employed in these instances, and it is more often prescribed to women, such as 'crazy cat lady', 'crazy dog lady', and so forth; it is rare to hear men described in this manner by others or themselves.

Indeed, the enjoyment felt by women equestrians, asserted in the diary extract below, is often described as a form of mental illness, such as addiction, obsessivecompulsive, and other pathologies.

Anonymous diary extract:

I enjoy everything about riding - the smell, the connection that you have when you ride, the trust and respect which builds a bond.

Very often, horses are seen as causes of some degree of mental conditions, as suggested by Toth (2000), who discusses the psychology of women and horses by explaining that children, especially girls, tend to be 'obsessed' by horses through images, pony rides, rocking horses, and other toys. She suggests, "Horse figurines, calendars, books, and stuffed animals are popular even with children who have never seen a horse except on television or in the movies through an imagined state. This 'horse-crazy girl' is a well-known caricature in modern societies" (Toth, 2000:32). Thus, many women equestrians have embraced this kind of mental illness language and moniker as part of their identities. For example, the following respondent refers to herself as 'mad' because of the depth of emotion and devotion she feels towards her horse over her human family:

Witney, aged 47, horse-owner:

I see him more than I see my children. I love him more, I think, than I love my children [laughs], and I think the children would probably say, 'yeah you do' [laughs], and my husband knows where his place is as well [laughs]. I do think after this interview you will probably think, 'yeah, she's mad', but when you see me with him, you'll realise the love, do you know what I mean, and how much I get back.

Another way women equestrians try to explain their passion and deep emotion along with justifying the costs of time, energy, and financial commitments is to frame their responses in work discourses. Therefore, their equestrianism is not a form of mental illness or perceived weakness, but rather a work responsibility, a literal labour of love. Frances (2013) argues that dedicating so much of oneself for recreational pursuits is not deemed as socially acceptable in current society; therefore, defending ardent behaviour in terms related to work is a way for people to legitimise their leisure activities. It is viewed as more acceptable to ourselves and to others to find meaning in work rather than hobbies or pleasurable experiences, which are seen as trivial and frivolous (Frances, 2013). The dedication that women interviewees show towards their horses is often rationalised in this manner.

Penelope, aged 59, horse-owner:

I see my horse every day even if I'm not riding him. I'll come up and say hello to him. 
I have a lesson once per week sometimes on my horse and sometimes on another horse depending upon how things are going or what l'm aiming to do. So, every day, well, I think about him everyday [laughs].

By regularly being on Penelope's mind even when she is not riding, is illustrative that her horse and riding is more than a diversion or pastime for her; interspecies connections are being fostered and maintained through fundamental physical work as well as emotional work of socialising with her horse and thinking about her horse's needs, both of which has mutual benefits for wellbeing and welfare.

In current society, daily routine, work commitments, family, and busy lifestyles continuously pressure and burden women, and, in alignment with the feminist critiques of Plumwood (1993), it emerged that the women interviewed for this research increasingly rely on horses for emotional support and escapism. Positive, mutual trustworthy relations are fundamental in securing the welfare and development of human-equine interactions, which blurs the boundaries between leisure and work to provide profound transformative experiences. For example, Joanne's statement below provides an example of the strong feelings she has in relation to riding horses. She compares it to an essential part of life - breathing. In the way that you need it to survive, she refers to riding as a thing she just has to do.

Joanne, aged 51, horse-owner:

It's like saying, 'what's your motivation for breathing' [laughs]. You can't not because you just have to do it.

Similarly, Keaveney (2008:7) states, "Outsiders do not share these feelings of sacredness; only the insiders, born into the tribe, recognize these feelings."

Also, these 'leisure as unpaid labour' narratives (Rojek, 2009) extend to rationalisations involving working on the self, such as self improvement and self esteem. When humans come into contact with horses, they begin to gain skills, which improves their senses of self and self images. Thus, their levels of self worth may improve as well as other talents and skills that they did not know existed can begin to emerge (Hallberg, 2008). Participants identified that the work they do with their horses has boosted their levels of confidence:

Ella, aged 14, horse-owner:

I have confidence and 'cos' of horse riding I'm a lot fitter as a person. I'm not lazy or anything like that. I'm always up here with my horse. I don't sit around. I'm always up here.

Jane, aged 55, Instructor and horse-owner:

I've had a very happy life with horses, and, if it hadn't been for the horses, I couldn't imagine l'd be the person I am today. It's made me a more confident person. It's built my confidence and built my esteem, built my ability to communicate and opens up a whole new world as well.

Keaveney (2008), similarly, discusses that riders develop self assurance through meeting challenges posed by horse ownership. Toth (2000:34) supports this, as her women-focused study found, "the experience of a successful interaction with a horse may change the course of her life by increasing her self confidence, self esteem, assertiveness, and willingness to take on difficult challenges." These advances in self improvement and commitments to emotional work validate the time and resources spent in this recreational pursuit. 


\section{Horse-related identities}

Through forging mutual bonds by developing empathetic relations with horses and by investing in equine recreation as a means of therapeutic 'work', this research also found emotional devotion to horses becomes a significant identity marker for women, where they formulate a horse-related sense of self usually from an early age. As Paige suggests below, this horse-related identity is often assembled with their gender identity.

Paige, aged 46, horse-owner:

I think it is a 'girl thing' because there's not that many men riding, is there? When you see kids riding here, there's not many little boys, is there? Maybe the odd one, and I just don't know, l've always loved horses from being small.

The formation of a horse-related identity in childhood can be seen to stay with women equestrians into adulthood. As Latimer and Birke (2009:2) argue, "different ways of investing horses with significance help manufacture distinctions between different kinds of people and constitutes different social worlds." Carron and Hausenblaus (1998) utilise theories of group cohesion to identify two main reasons for a sense of belonging based on shared interests and experiences: 1) involvement for predominantly social reasons; and, 2) satisfaction and pleasure derived from that social interaction for task reasons such as enjoyment of a group working as a team to complete a particular task. Other needs associated with social interaction involves meeting new people and involvement with like-minded people, which is evident in the following statements about human-equine interactions:

Belinda, aged 60, horse-owner:

While my children were growing up, it was the social aspect of it as well. You meet people and, well, particularly bringing children up now, to bring children into the world of horses, to teach them how to look after a horse and how to care for it and be kind. I just think it's really important, and l've had a fantastic 'horsey life' in that I've met some fantastic people that I'll remain friends with forever. It's been a lovely, extremely positive experience for me.

Witney, aged 47, horse-owner:

I've made a very solid circle of friends because you find that the people are likeminded. You realise that those people understand the pressures that you have to go through to have one [horse]. Not just the financial pressures, but the pressure on your time, the burden on your life. You know you can't take one on and ignore it. I mean, there's probably some people that do, but you take it on board like $110 \%$.

Witney's statement reinforces the importance of social support due to the huge commitments involved with horse ownership. Toth (2000) supports this statement, as she talks of women who have horses finding an immediate circle of friends amongst other women owners. This is due to the commonalities of interest. She mentions that there is a network of friends around the world who may be interested in the same breed or the same driving discipline, and there is an instant connection with anyone else involved with riding or owning horses (Toth, 2000). Within Keaveney's (2008) research, one of her participants similarly discussed that there was an instant affinity with horse people, expressing her development of gaining more 'real friendships' in the barn within a year in comparison with those since her college days. She mentioned that these are people with the same interests and beliefs, around whom she enjoys being and to whom she can relate easily, explaining that the horse world is its own universe; you have an instant 'in' when you own a horse (Keaveney, 
2008). This exposes a very tight knit, inclusive, and supportive community. It also indicates that the 'horse woman' identity is one that is very often positive and personally validating for inter-human as well as inter-species interactions.

\section{Conclusions}

Women's engagement with horses allows close bonded relationships to develop as a result of emotional attachment. Complex connections between women and horses are analysed within this research, where participants reveal the importance of intimate relations with horses through affection, mutual trust, and interdependency. Participants were aware of the 'otherness' surrounding horses; however, by respecting such differences, women were able to form closer bonds through sentimental and empathetic understanding. This was found to be reciprocated by horses, who behaved in emotionally caring ways towards their companion owners as well. Boundaries between horse and human as well as leisure and work have been blurred. This supports Latimer and Birke's (2009:4) "call to reassemble the social to include the non-human." Also apparent is the role that gender plays in human-equine relationships. Interactions with horses and approaches to horse wellbeing and welfare can be seen to be gendered (Dashper, 2017), and it is suggested women enjoy forming close relations with horses based on reciprocal affection and companionship. By performing classically feminised roles of carer and nurturer, women equestrian participants do not threaten the current gender order; however, their practices strengthen bonds with their horses, which improves mutual welfare and wellbeing. Such relationships, according to Dashper (2015:15) "contribute to understandings of how gender is done in everyday interaction" as well as "create gender within everyday lives."

This research has been set in what Danby (2017) terms equiscapes. The equiscape provides a conceptual space for complex human-equine interactions to take place. It is this leisure landscape which sits firmly at the core of such diverse multi-species interrelations, experiences, and emotions. It is here where boundaries between humans and non-human bodies become blurred and entangled through emotional recreation. As a result, this paper demonstrates how women and horses gain mutual physical, psychological, and social stimulation through such interactive experiences and an interdependence upon the companion partnership to coexist effectively. As part of the 'horse woman' identity, which is comprised of emotional experiences and encounters with horses, equiscapes are viewed as leisure 'working' environments, where investments in time, resources, and emotions are framed in work discourses in order to legitimise efforts and expenditure. The pressure to conform to societally constructed emotional norms dictates the appropriateness of emotion and its expression (Ruberg, 2010), and, in this way, emotions become to be viewed as more acceptable given collectively held socio-cultural ideology which values self improvement and physical work over recreational and hedonistic pursuits. In this way, the research contributes to understandings of women's emotional labour in interspecies relationships. Aligned with Haraway's (2003) notions of 'naturecultures' and the processes of different species 'becoming with' each other, this research also contributes to understandings of how women and horses perform across the natureculture divide and investigates how this has led women to re-negotiate their identities through serious leisure commitment, working to forge shared meaningful bonds with non-human companions.

\section{References}

Adams, C. and Donovan, J. (1999). Introduction. In C. Adams and J. Donovan (Eds.) 
Animals \& women: Feminist theoretical explorations. Durham, NC: Duke University Press.

Ahmed, S. (2004). The cultural politics of emotion. London: Routledge.

Barad, K. (2007). Meeting the universe halfway: Quantum physics and the entanglement of matter and meaning. Durham, NC: Duke University Press.

Birke, L. (2002). Intimate familiarities? Feminism and human-animal studies. Society and Animals, 10(4), 429-436.

Birke, L. and Brandt, K. (2009). Mutual corporeality: Gender and human/horse relationships. Women's Studies International Forum, 32, 189-197.

Birke, L., Hockenhull, J., Creighton, E. (2010). The horse's tale: Narratives of caring for/about horses. Society and Animals, 18, 331-347.

Braidotti, R. (2013). The Posthuman. Cambridge: Polity Press.

Brandt, K. (2004). A language of their own: An interactionist approach to humanhorse communication. Society and Animals, 12(4), 299-316.

British Horse Society (BHS) (2012) Equestrian statistics. http://bhs.org.uk.

Budiansky, S. (1997). The nature of horses: exploring equine evolution, intelligence, and behaviour. New York: The Free Press.

Butler, J. (2006) Gender Trouble. London: Routledge.

Carr, N. (2015). Dogs in the leisure experience. Oxford: CABI.

Carron, A.V. and Hausenblaus, H.L. (1998). Group dynamics in sport. Morgantown, Virginia: Fitness Information Technology.

Daly, B. and Morton, L. (2009). Empathetic Differences in Adults as a Function of Childhood and Adult Pet Ownership and Pet Type. Anthrozoös, 22(4), 371-382.

Danby, P. (2017). Post-humanist insight into human-equine interactions and wellbeing within the leisure landscape. In N. Carr and J. Young (Eds.) Animals and leisure: Rights and Wellbeing. Taylor and Francis.

Danby, P. and Hannam, K. (2016). Entrainment: Human-Equine Leisure Mobilities. In J. Rickly-Boyd, K. Hannam, M. Mostafanezhad (Eds.) Tourism and leisure mobilities: Politics, work and play. Contemporary Geographies of Leisure, Tourism and Mobility Series. London: Routledge.

Dashper, K. (2017). Human-Animal Relationships in Equestrian Sport and Leisure. In K.Daspher (Ed.) Human-Animal Relationships in Equestrian Sport and Leisure. London: Routledge.

Dashper, K. (2015). Strong, active women: (Re)doing rural femininity through equestrian sport and leisure. Ethnography, 1-19. 
Davis, D., Maurstad, A., Dean, S. (2014). My horse is my therapist: The medicalization of pleasure among women equestrians. Medical Anthropology Quarterly, 29(3), 298-315.

DeMello, M. (2012). Animals and Society: An Introduction to Human-Animal Studies. New York: Columbia University Press.

Feder, H. (2014). Ecocriticism, Posthumanism, and the Biological Idea of Culture. In Garrard, G. (Ed.) Oxford Handbook of Ecocriticism. Oxford: Oxford University Press.

Frances, A. (2013). Saving normal: An insider's revolt against out-of-control psychiatric diagnosis, DSM, big pharma, and the medicalization of ordinary life. New York: William Morrow.

Franklin, A. (1999). Animals and Modern Cultures: A Sociology of Human-Animal Relations in Modernity. London: Sage Publications.

Fullagar, S. and Pavlidis, A. (2017) Feminist theories of emotion and affect in sport. In B. Wheaton, J. Cauldwell, J. Mansfield, B. Watson (Eds,) Handbook of Feminism in Sport, Leisure and Physical Education. London: Palgrave.

Game, A. (2001). Riding: Embodying the Centaur, Body and Society, 7(4), 1-12.

Gruen, L. (2011). Ethics and Animals. An Introduction. Cambridge: Cambridge University Press.

Hallberg, L. (2008). Walking the Way of the Horse: Exploring the Power of the Horse-Human Relationship. New York: iUniverse.

Hama, H., Yogo, M., Matsyyama, Y. (1996). Effects of stroking horses on both humans' and horses' heart rate responses. Japanese Psychology Research, 38(2), 66-73.

Hamilton, J. (2011). 'Caring/sharing': Gender and horizontal co-ordination in the workplace. Gender, Work, and Organization, 18(1), 23-48.

Haraway, D. (2003) The Companion Species Manifesto: Dogs, People and Significant Otherness. Chicago: Prickly Paradigm Press.

Hausberger, M., Roche, H., Henry, S., Visser, E. (2008). A review of the humanhorse relationship. Applied Animal Behaviour Science, 109(1), 1-24.

Henry, S., Hemery, D., Richard, M., Hausberger, M. (2005). Human-mare relationships and behaviour of foals toward humans. Applied Animal Behaviour Science, 93, 341-362.

Herzog, H. (2017). Gender differences in human-animal interactions: A review. Anthrozoös, 20(1), 7-21.

Hochschild, A. (1983). The Managed Heart. Berkeley, CA: University of California Press.

Husso, M. and Hirvonen, H. (2012). Gendered agency and emotions in the field of care work. Gender, Work, and Organization, 19(1), 29-51. 
Irwin, C. (1998). Horses Don't Lie. New York: Marlowe and Company.

Jones, B. (1983). Just crazy about horses: the fact behind the fiction. In Katcher, A.H., and A.M. Beck, (Eds.), New Persepctives on our Lives with Companion Animals, Philadelphia: University of Pennsylvania Press, 87-111.

Keaveney, S. (2008). Equines and their human companions. Journal of Business Research, 61, 444-454.

Knight, J. (Ed.) (2005). Animals in person: Cultural perspectives on human-animal intimacies. Oxford: Berg.

Latimer, J. and Birke, L. (2009). Natural relations: horses, knowledge, technology. The Sociological Review, 57(1), 1-27.

Latour, B. (1988) The pasteurization of France. Cambridge, MA: Harvard University Press.

McCormick, A., McCormick, M., McCormick, T. (2000). Horses and the Mystical Patch. Novato, CA: New World Library.

Markwell, K. (2015). Birds, Beasts and Tourists: Human-Animal relationships in tourism. In K. Markwell (Ed.) Animals and tourism: Understanding diverse relationships. Bristol: Channel View.

Mills, D. and McNicolas, J. (2005). The rider-horse relationship. In D. Mills and S. McDonnell (Eds.) The domestic horse: The origins, development and management of its behaviour. Cambridge: Cambridge University Press.

Nishikawa, M. (2011). (Re)defining care workers as knowledge workers. Gender, Work, and Organization, 18(1), 118-136.

Philo, C. and Wilbert, C. (2000). Animal spaces, beastly places: An introduction. In C. Philo, and C. Wilbert (Eds.), Animal spaces, beastly places, new geographies of human-animal relations, 1-34.

Plumwood, V. (1993) Feminism and the Mastery of Nature. London: Routledge.

Roberts, M. (2002). Horse Sense for Horse People. New York: Penguin Books.

Robinson, I. (1999). The human-horse relationship: How much do we know?. Equine Veterinary Journal, 28, 42-45.

Rojek, C. (2009). The labour of leisure: The culture of free time. London: Sage Publications.

Ruberg, W. (2010). Introduction. In W. Ruberg and K. Steenbergh (Eds.) Sexed sentiments: Interdisciplinary perspectives on gender and emotion. Amsterdam: Rodopi.

Swan, E. (2008). 'You make me feel like a woman': Therapeutic cultures and the contagion of femininity. Gender, Work, and Organization, 15(1), 88-107. 
Toth, D. (2000). The Psychology of Women and Horses. In R. Berman (Ed.) Of Women and Horses. California: Bow Tie Press, 31-41.

Traeen, K. B., Wang, C. (2006). Perceived Gender Attribution, Self-Esteem, and General Self-Efficacy in Female Horseback Riders. Journal of Equine Veterinary Science, 26(10), 439-444.

Wilbert, C. (2009). Animal geographies. International encyclopedia of human geography, 122-126.

Wolfe, C. (2013). What is posthumanism?. Minneapolis: University Of Minnesota Press. 